\title{
Opportunities and challenges for Mexico-U.S. cooperation in ocean sciences
}

\author{
Agustín Ayala-Castañares \\ Unizersidad Nacional Autónoma de México • Mexico City Mexico \\ Robert A. Knox \\ Scripps Institution of Oceanography • University of California - San Diego USA
}

\section{Introduction}

In an academy-to-academy effort that is novel for the ocean sciences, a Mexico-U.S. Joint Working Group (JWG) on Ocean Sciences was created in 1995 by the U.S. National Research Council (NRC) and the Academia Mexicana de Ciencias (AMC). The purpose of the JWG was to take "a further step to consolidate the conduct of ocean science between the two countries and to better integrate the ocean interest and understanding of the two countries." To do so, it identified several examples of marine research topics for which binational cooperation could yield greater advances than solely national efforts. The advantages of binational cooperation derive fundamentally from the border-spanning nature of the oceanic processes and phenomena of interest, and from the insight to be gained by comparing and contrasting oceanographic phenomena applying a regional approach. The JWG also identified a number of other enabling actions that could be taken by the two governments, by scientific organizations, or by individual scientists of the two nations to improve the effectiveness and impact of binational research efforts. The recommendations of the JWG are given in a report (henceforth "the Report") in English and Spanish (NRC and AMC, 1999).

The JWG was fully binational, with U.S. and Mexican co-chairs (the authors), and its membership spanned the disciplines of marine science. While some of its recommendations are directed to one nation or the other, all of them were developed in an atmosphere of frank and open discussion in the entire group.

\section{Examples of Research Areas}

Much of the Report is devoted to discussion of research areas that are poised for advances through binational cooperative efforts. The JWG was clear that these are examples only, not a complete list. Other topics not mentioned in the Report may be equally ripe for binational attention. The JWG could not claim within its own membership a uniform and comprehensive coverage of the entire scope of marine science pertinent to this binational setting. It posed examples to stimulate further thought and action by the larger science communities of the two nations and by their respective governments and science agencies. In highly summarized form, these examples include:

California Current System. The current crosses the border, inextricably linking the two countries in questions of ocean circulation and variability of the associated ecosystems.

Marine Birds and Mammals. Many important species breed exclusively or primarily in very limited sites along the Pacific coast or in the Gulf of California, some of them threatened by human activities, and these animals follow migratory patterns that include both countries.

Laminated Sediments. Fish scales in finely laminated sediments afford a 2000-year record of variations in populations of sardines and anchories in the Pacific region, a record from which more remains to be learned.

Border Arca Pollution. The range of contaminants introduced into the marine environment surrounding the U.S. - Mexico border region is extensive. Among the contaminants that should be studied are bacteria and pathogens, particulate organic matter and solids, trace metals, synthetic organic chemicals, and products of oil exploration and production.

Sediment Transport in the Upper Gulf of California. U.S. use of Colorado River water impacts sediment input to 
the entire Gulf of California. Extremely large tides in the upper Gulf drive strong mixing and thus large concentrations of suspended material. Sediment distributions and transports, and implications for future shoreline erosion, are poorly known.

Tectonic Development of the California Borderland and the Gulf of California. The crustal evolution of the geological system consisting of the Borderland region west of Baja California and Southern California, the Gulf of California, and the Baja California peninsula poses a number of unresolved basic questions, best approached through unified studies of the marine and terrestrial geology of the entire region.

Sediment-Smothered Hydrothermal Vents. The seafloor hydrothermal vent environments in the Gulf of California are remarkable sites for interdisciplinary studies of ecological, biogeochemical and geophysical processes at ocean spreading centers. This Mexican area is a unique laboratory with a rich array of natural experiments in progress, and is of strong interest to both countries and to the international scientific community.

Circulation in the Intra Americas Sea (IAS). The roots of the western boundary current of the North Atlantic Ocean lie in the Loop Current / Florida Current system. The time-varying flow is of fundamental importance for exchanges and transports of organisms, substances, sediments and pollutants between the Caribbean Sea and the Gulf of Mexico, and between the U.S. and Mexico. Operational circulation forecasting of this basin-scale region is possible, given integrated efforts in observations and modelling.

Biophysical Coupling in the IAS. It is clear that the timedependent physical circulation is highly important to larval transport and primary productivity in this region. The ability to model and predict variations of the IAS ecosystems, particularly the rich fisheries, would be of enormous value to both nations, and well worth the research effort required to accomplish this goal.

River Plumes. The Mississippi River outflow leads to a time-varying zone of hypoxia along the Louisiana coast, a consequence of high nutrient pulses in the river water. Extending such studies to Mexican rivers could build on the Mississippi experience and advance understanding by comparing and contrasting the various situations with respect to nutrient inputs and nearshore circulations.

Sediment Dynamics. Land-ocean interactions in the Gulf of Mexico affecting the sedimentary environment include a wealth of processes: river outflows both large and small, shelf-deep water interactions due to Loop Current rings, and impacts of human activ- ities such as dams and coastal structures. The region as a whole affords a wide range of sites and possibilities for basic studies of the factors that govern sediment transport and distribution.

Oil-and Gas-Associated Seeps. The thick salt deposits (diapirs) of the northern Gulf of Mexico extrude through sediments and harbor unique benthic communities of organisms. Such communities have not yet been observed or studied in the southern Gulf. A study of this kind could expand our basic knowledge of these life forms and could also be of assistance in oil and gas exploration, as has been the case in the U.S. portion of the Gulf.

Marine Enzironmental Quality. Knowledge of the concentrations and fates of various pollutants in the marine environment of the IAS is needed by both nations. This is particularly true of petroleum, but also of pesticides and agricultural chemicals. Many key marine species that can be monitored for their responses to various pollutants have already been identified. Repeated surveys of selected species throughout the region are needed.

Marine Natural Products. Particularly in Mexican waters, with relatively unstudied but biologically rich environments like coral reefs, opportunities for the discovery of new marine substances abound. Some of the substances may find commercial use in pharmaceutical or industrial applications. This area of research affords a path to build up Mexican ability to understand and exploit its own marine natural products.

\section{Recommendations}

The principal recommendation of the Report is for agencies in both countries to recognize that there are numerous research areas, some of them noted above, in which better-supported joint work by U.S. and Mexican scientists could yield both substantial scientific advances and practical advantages to both nations. Although this would certainly require increased funding, and is therefore a difficult goal in today's tight funding climate in both nations, it is also a plea for attention by U.S. and Mexican agencies to the positive synergy that can arise if scientific problems are addressed without artificial constraints due to the location of borders. Ocean circulations in the Pacific and IAS connect the two countries, so unified study of the natural phenomena, not independent studies delimited by the borders, will be most fruitful. It is up to coalitions of scientists to define, advocate and carry out these binational research efforts. The Report cites examples of likely research areas but is deliberately not itself an implementation plan. It can serve as a useful reference point and a basis for the assembly of scientific coalitions.

Several other positive actions apart from enhanced financial support of particular binational research pro- 
grams are noted in the Report. It is clear that a major concern is to strengthen the Mexican marine research infrastructure, so that Mexican marine research groups can become more numerous, better supported, and more capable of cooperating on equal terms with U.S. counterparts. Specific actions include increased scholarly exchanges, better Mexican support of Mexican research group infrastructure (technical staff, equipment), and the provision of modest amounts of funds to institutions whose purpose is to foster binational programs, for example, the U.S.-Mexico Foundation for Science.

Additional recommended actions include three that are specifically directed toward Mexico. The first of these is the establishment of a Mexican equivalent of NOAA. This would enhance binational dialogue and cooperation on a range of ocean monitoring and resource management issues. In the non-governmental sector, establishment of a Mexican analogue to the Ocean Studies Board is recommended. These actions would create parallel institutions that would interact on an equal footing, and on subjects of common interest, and would naturally foster a greater degree of binational research cooperation. The third action is for the Mexican system to secure balanced funding for its small but capable fleet of research vessels. These are excellent vessels, but unless attention is paid to their maintenance and equipment, and unless support is available to scientific groups to use them, the substantial capital investment in them will be lost as the ships age.

A recommendation concerning scholarly publications is directed primarily at the United States. Two factors combine to place Spanish-speaking scientists, and Spanish-language scientific publications, at an unwarranted disadvantage. The first is the tendency of the major citation indexes to price their services and to stipulate other costly requirements such that most journals from developing countries cannot afford to be listed. The second, more amenable to remedy by the simple individual exercise of international collegiality and understanding within the scientific community, is overly negative treatment of manuscripts submitted to English journals by authors whose first language is not English. Without accepting poor science, English-speaking editors and reviewers, whose own work is made much easier by the de facto predominance of English in global scientific communication, can work a little harder to include and polish papers from colleagues when those papers are scientifically sound, but perhaps lacking in English refinements. English speakers can also improve their basic awareness of the Spanish scientific literature.

While most funding for enhanced collaborations in ocean sciences will inevitably have to come from U.S. and Mexican science agencies, there are two other possibilities with modest promise. The North American Free Trade Agreement (NAFTA) already includes a Commission for Environmental Cooperation (CEC). Proposal pressure for marine environmental projects that fit CEC guidelines should be brought to bear. And both governments, perhaps in coordination with the appropriate professional societies, should encourage greater industrial support of joint marine research activities, since important industrial sectors in both nations (petroleum, fisheries, etc.) will increasingly need the kinds of information that such research can provide in order to manage their industrial operations in a sustainable manner and in harmony with the ocean environment.

A recommendation for enhanced cross-border communication and scientific exchange stems from the realization that each national ocean science community lacks full awareness of relevant activities and progress in the other, and that both communities are widely distributed geographically in their respective countries. Joint symposia, sabbatical visits and visiting lectureships could improve mutual awareness and interaction at modest cost. Enhanced use of the internet and broadband, high speed communications links could foster these exchanges of ideas and information. Some groups of universities already have high capacity cross-border links, including video capability. These could form the nuclei of regional networks that could carry not only ocean science traffic but other types of scientific, educational and policy interactions.

A related aspect of cross-border exchange concerns databases. Oceanographic data holdings are dispersed among universities, government agencies and other bodies in both countries. In the U.S., a degree of coordination and commonality is provided by the National Oceanographic Data Center. In Mexico this function does not exist at present, due to improper support from the government authorities. The report suggests that INEGI (Instituto Nacional de Estadística, Geografía e Informática) could be the appropriate body to take on this task. To the extent that data holdings can be made more readily accessible to researchers both within and between the two countries, binational scientific progress will accelerate.

A final recommendation concerns the mutual respect without which no international enterprise can succeed, and deserves an extended quotation: "...attention should be devoted to developing a legal framework and ethics code for the conduct of joint oceanographic research between Mexico and the United States. The laws and regulations of both countries and the United Nations Convention on the Law of the Sea provide a legal framework for binational ocean sciences, and should be fully respected by scientists of both countries. There is a perception among some scientists in Mexico that U.S. scientists have not adequately involved Mexican scientists in research conducted in Mexican waters and have not shared data and publication rights. Such behavior would counteract all the positive efforts mentioned elsewhere in this report and should be avoided at all costs. An important means to meet expectations of joint research is to reach specific agreements about duties, responsibilities, joint or separate author- 
ship of publications, credit, patent rights and timetables prior to conduct of the research. Mutually agreed-upon means to streamline the legal requirements surrounding research activity could, in some cases, lead to more productive research efforts. Both governments, particularly the Department of State in the United States and the Ministry of Foreign Affairs (Secretaria de Relaciones Exteriores) in Mexico, should respond to the advice of their respective scientific communities by identifying and establishing such streamlined procedures."

\section{Conclusion}

The political boundaries between U.S. and Mexican ocean areas have given rise, generally by accident, inattention, or the simple convenience of working on one side of a line, to a number of situations in which marine scientific initiatives have been limited by the border rather than optimized to address the oceanic phenomena of importance, or have not been pursued at all. A higher degree of binational awareness of these important research problems, and a higher degree of coordination in addressing them, can pay dividends to both nations in basic scientific understanding and in more practical areas like fisheries management, pollution control, and environmentally sound petroleum produc- tion. The Report of the JWG, and indeed the personal cross-border connections formed by JWG members in the course of their work, can serve as one means to encourage the marine scientific communities of both nations to take stock of the research opportunities that exist, and then to band together to secure from their governments the means to address them with energy, intelligence, and genuinely collegial U.S.-Mexican collaboration.

\section{Acknowledgments}

We are indebted to all our JWG colleagues, to E. Urban of the NRC Staff for his wise guidance and support of the entire project, and to E. Aguayo, L. Soto, F. Vidal-Lorandi and V. Vidal-Lorandi, members of the Mexican JWG for their extended efforts on the Spanish text of the Report.

\section{REFERENCE}

National Research Council and Academia Mexicana de Ciencias, 1999: Building Ocean Science Partnerships: The United States and Mexico Working Together. National Academy Press, Washington, D.C. One volume, in English (127 pp.) and Spanish (140 pp.).

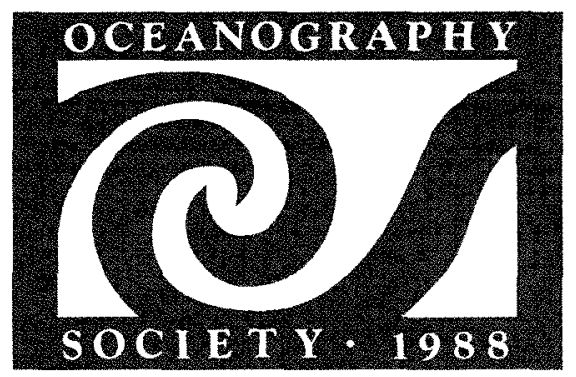

